\title{
Studi mechanical properties dan struktur mikro hasil variasi temperatur dan waktu aging pada alumunium matrix composite (AMC) hasil proses stir casting dengan kandungan matrix berlebih
}

\author{
Iman Saefuloh ${ }^{1)}$, Agus Pramono ${ }^{2)}$, Reinhart Bonke ${ }^{3)}$, Yazid Rukmayadi ${ }^{4}$ \\ ${ }^{1,3,4}$ Jurusan Teknik Mesin, Universitas Sultan Ageng Tirtayasa, Banten, Indonesia \\ ${ }^{2}$ Jurusan Teknik Metalurgi, Universitas Sultan Ageng Tirtayasa, Banten, Indonesia \\ "E-mail : iman.saefuloh@ untirta.ac.id
}

\begin{abstract}
Abstrak
Alumunium matrix composite (AMC) banyak digunakan sebagai bahan di banyak bidang (otomotif, pertambangan, penerbangan, pertahanan) karena ringan, dipilih sebagai material ini ringan dan relatif murah dan mudah difabrikasi. Proses pembuatan AMC tidak mudah karena matrik dapat membentuk gumpalan. Proses Stir casting dipilih dalam proses ini karena dapat menghasilkan AMC lebih merata dan dapat memecah gumpalan tersebut. Setelah stir casting dilakukan proses perlakuan panas aging agar material hasil lebih baik. Penelitian ini bertujuan menggunakan alumunium sebagai matrik dan senyawa karbida $\mathrm{SiC}$ sebagai penguat dengan proses aging suhu $100^{\circ} \mathrm{C}$ dan $200^{\circ} \mathrm{C}$ dengan waktu penahanan selama 1, 2, 3 dan 4 jam untuk meningkatkan mechanical properties dan memperbaiki struktur mikro. Setelah melalui proses pengujian didapatkan waktu aging berpengaruh terhadap mechanical properties yang di hasilkan, semakin lama waktu aging semakin besar pula kenaikan mechanical properties, untuk nilai kekuatan tarik naik sampai 70\% dan kekerasan naik sampai $31 \%$.
\end{abstract}

Kata Kunci: Alumunium matrix composite, waktu aging, variasi temperatur, stir casting.

\begin{abstract}
Aluminum matrix composite (AMC) is widely used as the material in many fields (automotive, mining, aviation, defense) because it is lightweight, relatively inexpensive and easily fabricated material. The process of making AMC is not easy because the matrix can form clumps. In this study, the Stir casting process was chosen because it could produce AMC more evenly and can break the clumps. After the stir casting process, the aging heat treatment process was carried out in order to produce better material. This study aimed to use aluminum as a matrix and SiC carbide compounds as reinforcement with an aging process of $1000 C$ and $2000 C$ with a holding time of $1,2,3$ and 4 hours to improve mechanical properties and improve microstructures. After going through the testing process, it is found that the aging time affected the mechanical properties that were produced; the longer the aging time, the greater the mechanical properties increased, with the tensile strength value increased to $70 \%$ and the hardness increased to $31 \%$.
\end{abstract}

Keywords: aging, Mechanical properties , Alumunium matrix composite, stir casting 


\section{PENDAHULUAN}

Penggunaan bahan dasar logam telah lama dikembangkan untuk produk industri sebab mempunyai beberapa keunggulan baik sifat mekanis, elektrik maupun yang lain. Pemilihan material untuk suatu komponen atau strukturnya umumnya menyangkut beberapa aspek, yaitu: aspek kekuatan spesifik, kekakuan, ringan, tidak korosif dan ketahanan atau umur material [1]. Pada umumnya alumunium banyak digunakan karena material ini ringan dan relatif murah dan mudah difabrikasi. Permasalahannya adalah material ini mempunyai kekuatan yang lebih rendah dibandingkan material komersil lainnya seperti besi tuang, baja maupun tembaga [2]. Namun alumunium dapat ditingkatkan kekuatannya dengan melalui proses pemaduan (alloying), proses pengerjaan dingin (cold working) dan perlakuan panas (heat treatment) serta proses penuaan (aging) [3]. Untuk menangani permasalahan tersebut, diperlukan adanya pemilihan bahan komposit berupa senyawa karbida $\mathrm{SiC}$ yang memiliki sifat kekerasan yang tinggi dan ketahanan pada lingkungan bertemperatur tinggi dengan matrik paduan Alumunium- Tembaga-Magnesium(Al-Cu-Mg) [4-8].

Perlakuan yang diberikan pada logam antara lain adalah perlakuan panas atau heat treatment, yang merupakan suatu proses perlakuan terhadap logam dengan cara memberikan pemanasan dan kemudian dilakukan pendinginan dengan media pendingin tertentu, untuk mengubah sifat mekanik. Dengan adanya pemanasan dan pendinginan pada kecepatan tertentu maka bahan-bahan logam akan memperlihatkan perubahan strukturnya sehingga sifat mekaniknya dapat diubah sesuai dengan yang diinginkan $[7,8]$.

Aluminium Matrix Composites (AMC) adalah jenis material komposit logam dimana aluminium sebagai matriknya dengan Cuprum $(\mathrm{Cu})$, Silikon karbida $(\mathrm{SiC})$ dan Magnesium (Mg) sebagai penguat dari matrik Aluminium. AMC mempunyai prospek pengembangan yang cukup menjanjikan, didasari oleh sifat-sifatnya yang baik, seperti kekerasan dan kekuatan yang tinggi, dan bahan dasar yang mudah didapatkan. Sifat mekanik alumunium biasa dikarakterisasi atau disesuaikan sesuai keinginan dengan memberikan suatu perlakuan khusus, sehingga dapat menghasilkan suatu logam sesuai dengan yang diinginkan, dalam sebuah penelitian yang telah dilakukan, metode aging (penuaan) dapat meningkatkan sifat 
mekanis pada material alumunium 6068 dalam hal ini kuat tarik dan kekerasannya dengan mevariasikan waktu tahan 1,5 , dan 8 jam pada temperature $180^{\circ}$ dan $200^{\circ}$ dan membandingkannya dengan material yang tidak diberikan perlakuan panas (aging) [9].
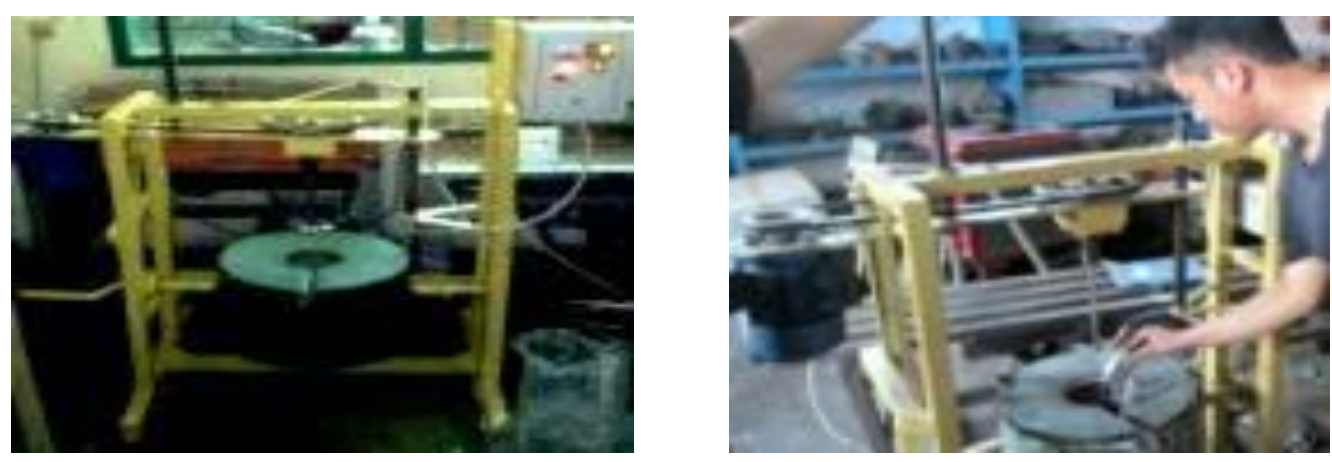

Gambar 1. Mesin stir casting

Salah satu metode yang dipakai dalam Pengecoran AMC dengan Penguat Tembaga $(\mathrm{Cu})$, Magnesium $(\mathrm{Mg})$ dan Silikon Karbida $(\mathrm{SiC})$ adalah teknik stir casting, metode yang digunakan dalam teknik ini adalah proses pengadukan dengan variasi putaran pada masing-masing tahap pengecoran. Metode Stir casting adalah suatu proses dari produk komposit dimana material penguat (reinforced) digabungkan dalam cairan logam dengan cara pengadukan. Pemilihan proses Stir casting dalam pembuatan material ini dikarenakan teknik ini dapat membuat komposit logam dengan distribusi partikel penguat yang merata dan homogen untuk mendapatkan sifat mekanik yang baik [10].

Peningkatan sifat mekanis terus meningkat seiring bertambahnya waktu penahanan dibuktikan dengan data pengujian yang dihasilkan. Nilai uji tarik meningkat dari 24,45 Kgf/mm2 menjadi 30,24 Kgf/mm2 sebelum dan sesudah diberikannya perlakuan panas (aging) begitu pula dengan kekerasannya yang meningkat dari sebelum diberikan perlakuan panas (aging) 79,6 BHN menjadi 94,5 BHN setelah diberikan perlakuan panas (aging), Dengan memanfaatkan hasil penelitian - penelitian sebelumnya, pada penelitian ini mencoba mengembangkan pembuatan alumunium paduan baru dengan 6 proses Stir casting dan aging [11], 
Dalam penelitian kali ini penulis bertujuan melakukan studi perlakuan panas dan aging pada alumunium matrix komposit (AMC) Alumunium dengan komposisi matrik $5 \% \mathrm{Cu}-4 \% \mathrm{Mg}-15 \% \mathrm{SiC}$ dengan sifat mekanik yang dihasilkan dan pengamatan struktur mikro.

\section{METODOLOGI PENELITIAN}

Bahan yang digunakan dalam penelitian ini adalah $\mathrm{Al}-5 \% \mathrm{Cu}-4 \% \mathrm{Mg}-15 \% \mathrm{SiC}$ proses pengecoran menggunakan metode Stir casting, kemudian Proses solution treatment yaitu memanaskan specimen pada temperature $500^{\circ} \mathrm{C}$ dengan waktu tahan 1 jam, dilakukan pemanasan sampai mencapai temperature 500 Solution treatment, quenching, setelah itu Proses Quenching yaitu mendinginkan dengan cepat specimen yang telah dipanaskan. Media yang digunakan untuk quenching adalah oli selama 5 menit. Proses Aging dilakukan setelah proses solution treatment dan quenching yaitu memanaskan kembali spesimen dengan memvariasikan waktu tahan $1,2,3$, dan 4 jam) pada temperatur $100^{\circ} \mathrm{C}$ dan $200^{\circ} \mathrm{C}$, Proses pendinginan udara setelah di aging. Untuk mengetahui sifat mekanik yang dari AMC yang dihasilkan maka dilakukan pengujian sifat mekanik yaitu; Uji kekerasan, Uji tarik dan Uji Impak. Sementara untuk mengetahui srtruktur mikro maka dilakukan pengamatan dengan Scaning elektro mikroskop (SEM).

\section{HASIL DAN PEMBAHASAN}

\section{a. Hasil Pengujian Tarik}

Specimen di uji Tarik di buat seperti standar ASTM E8M-09 dapat kita lihat pada gambar 2. Pengujian tarik material aluminium paduan hasil perlakuan panas dilakukan dengan kondisi specimen pada temperatur ruangan $23^{\circ} \mathrm{C}$, benda uji dengan ukuran specimen yang telah ditentukan diseting kecepatannya 10 $\mathrm{mm} / \mathrm{menit}$. 

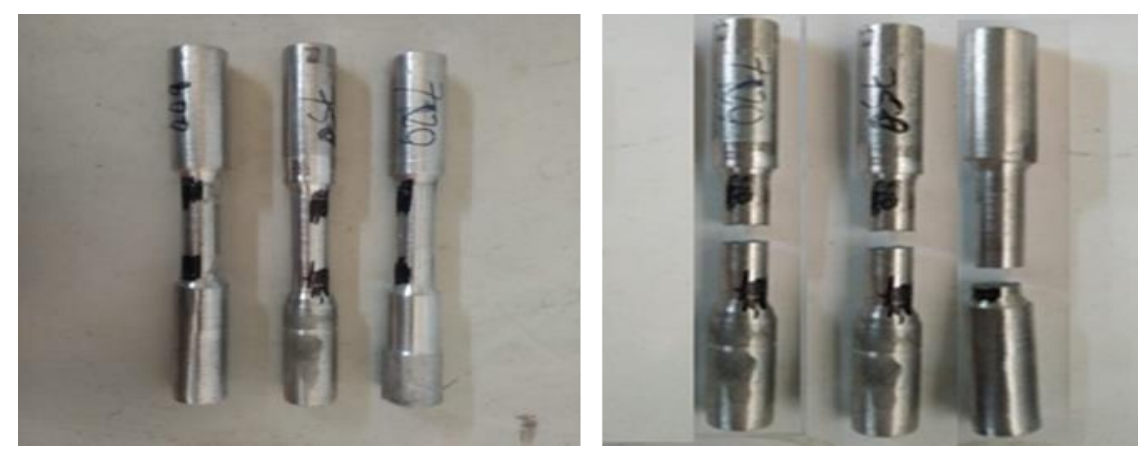

Gambar 2. Spesimen Uji tarik

Berdasarkan data pengujian tarik material paduan $\mathrm{Al}, \mathrm{Cu}, \mathrm{Mg}$, dan $\mathrm{SiC}$ dapat kita lihat table 1, kenaikan temperature berpengaruh terhadap sifat tariknya, peningkatan nilai temperature mengakibatkan kekuatan tarik semakin turun, namun waktu aging mengakibatkan kenaikan nilai kekuatan tarik yang signifikan, dapat dilihat bahwa nilai tertinggi dihasilkan pada specimen aging dengan suhu $100^{\circ} \mathrm{C}$ selama 4 jam sebesar $66,7 \mathrm{~N} / \mathrm{mm} 2$. Jika dibandingkan dengan nilai kuat tarik non aging sebesar 39,3 N/mm2 maka kenaikannya sampai 70\%. sedangkan pada aging $200^{\circ} \mathrm{C}$ nilai kekuatan tarik terbesar dimiliki waktu aging selama 4 jam sebesar 60,6, namun demikian jika dibandingkan dengan kekuatan tarik tanpa aging masih mengalami kenaikan sebesar penurunan nilai kuat tarik sebesar 54\%, Namun demikian jika dibandingkan antara temperature aging $200^{\circ} \mathrm{C}$ dengan pada aging temperature $100^{\circ} \mathrm{C}$ mengalami Penurunan harga kekuatan sekitar $12 \%$, ini disebabkan karena semakin getasnya material paduan seiring dengan naiknya suhu aging.

Tabel 1. Nilai kekerasan

\begin{tabular}{|c|c|c|}
\hline No & Spesimen & Hasil UJi Tarik $\left(\mathrm{N} / \mathrm{mm}^{2}\right)$ \\
\hline 1 & Non Aging & 39,3 \\
\hline 2 & Aging $\mathrm{T}=100^{\circ} \mathrm{C}, \mathrm{t}=1 \mathrm{jam}$ & 60,4 \\
\hline 3 & Aging $\mathrm{T}=100^{\circ} \mathrm{C}, \mathrm{t}=2 \mathrm{jam}$ & 63,9 \\
\hline 4 & Aging $\mathrm{T}=100^{\circ} \mathrm{C}, \mathrm{t}=3 \mathrm{jam}$ & 62,2 \\
\hline 5 & Aging $\mathrm{T}=100^{\circ} \mathrm{C}, \mathrm{t}=4 \mathrm{jam}$ & 66,7 \\
\hline 6 & Aging $\mathrm{T}=200^{\circ} \mathrm{C}, \mathrm{t}=1 \mathrm{jam}$ & 44 \\
\hline 7 & Aging $\mathrm{T}=200^{\circ} \mathrm{C}, \mathrm{t}=2 \mathrm{jam}$ & 47,5 \\
\hline 8 & Aging $\mathrm{T}=200^{\circ} \mathrm{C}, \mathrm{t}=3 \mathrm{jam}$ & 56,3 \\
\hline 9 & Aging $\mathrm{T}=200^{\circ} \mathrm{C}, \mathrm{t}=4 \mathrm{jam}$ & 60,6 \\
\hline
\end{tabular}




\section{b. Hasil Pengujian Kekerasan}

Pengujian kekerasan pada penelitian ini dilakukan dengan menggunakan metode brinell dengan standar SNI 19-0405-1989. Pengujian ini menggunakan alat uji kekerasan "Frank Welltest" dengan indentor $5 \mathrm{~mm}$, diberikan beban pada specimen dengan sebesar 62,5 kgf specimen ditunjukan pada gambar 3.
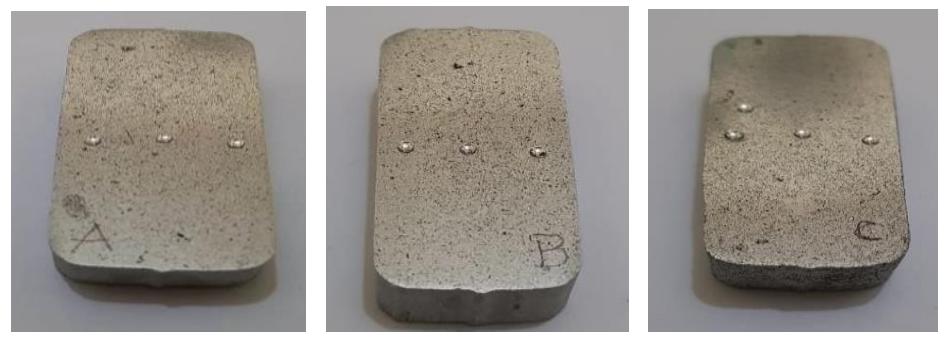

Gambar 3. Spesimen Uji Kekerasan

Tabel 2. Nilai kekerasan

\begin{tabular}{|c|l|c|}
\hline No & \multicolumn{1}{|c|}{ Spesimen } & Nilai Kekerasan $($ BHN) \\
\hline 1 & Non Aging & 76,2 \\
\hline 2 & Aging $\mathrm{T}=100^{\circ} \mathrm{C}, \mathrm{t}=1$ jam & 78,9 \\
\hline 3 & Aging $\mathrm{T}=100^{\circ} \mathrm{C}, \mathrm{t}=2 \mathrm{jam}$ & 84,6 \\
\hline 4 & Aging $\mathrm{T}=100^{\circ} \mathrm{C}, \mathrm{t}=3 \mathrm{jam}$ & 96,2 \\
\hline 5 & Aging $\mathrm{T}=100^{\circ} \mathrm{C}, \mathrm{t}=4 \mathrm{jam}$ & 99,6 \\
\hline 6 & Aging $\mathrm{T}=200^{\circ} \mathrm{C}, \mathrm{t}=1 \mathrm{jam}$ & 77,3 \\
\hline 7. & Aging $\mathrm{T}=200^{\circ} \mathrm{C}, \mathrm{t}=2 \mathrm{jam}$ & 89,2 \\
\hline 8. & Aging $\mathrm{T}=300^{\circ} \mathrm{C}, \mathrm{t}=3 \mathrm{jam}$ & 93,4 \\
\hline 9. & Aging $\mathrm{T}=300^{\circ} \mathrm{C}, \mathrm{t}=4$ jam & 98,7 \\
\hline
\end{tabular}

Berdasarkan tabel 2 nilai kekerasan dari material pengecoran mengalami peningkatan setelah dilakukan proses aging. Pada aging temperature $100^{\circ} \mathrm{C}$ jika dibandingkan dengan material hasil Stir casting non aging mengalami peningkatan nilai kekerasan material sebesar $31 \%$ dari hasil perlakuan non aging dengan nilai kekerasan 76,2 $\mathrm{HB}$ menjadi 99,6 HB, dan pada aging temperature $200^{\circ} \mathrm{C}$ selama jam mengalami kenaikan 30\% dengan nilai kekerasan 76,2 menjadi 98,7 HB. Kenaikan nilai kekerasan tersebut disebabkan karna unsur SiC dan $\mathrm{Mg}_{2} \mathrm{Si}$ menyebar merata sehingga kekerasan bertambah naik.

\section{c. Pengamatan Struktur Mikro}

Hasil pengamatan struktur mikro ditunjukan pada gambar 4, dari hasil pengamatan struktur mikro material hasil pengecoran dengan tanpa perlakuan aging terdapat fasa $\mathrm{Al}-\mathrm{Mg}_{2} \mathrm{Si}$ dimana fasa Alumunium (berwarna terang) dan Studi mechanical properties dan struktur mikro hasil variasi temperatur dan waktu aging pada alumunium matrix composite (AMC) hasil proses stir casting dengan kandungan matrix berlebih (Iman Saefuloh, dkk.) 
$\mathrm{Mg}_{2} \mathrm{Si}$ (berwarna kelabu kehitam-hitaman) dengan adanya fasa ini akan meningkatkan kekuatan nilai kekerasan pada alumunium paduan. Terlihat bahwa partikel $\mathrm{Mg}_{2} \mathrm{Si}$ dan $\mathrm{SiC}$ kurang terdistribusi merata dan menyebabkan nilai kekerasan pada sampel non aging lebih rendah dari sampel setelah aging.

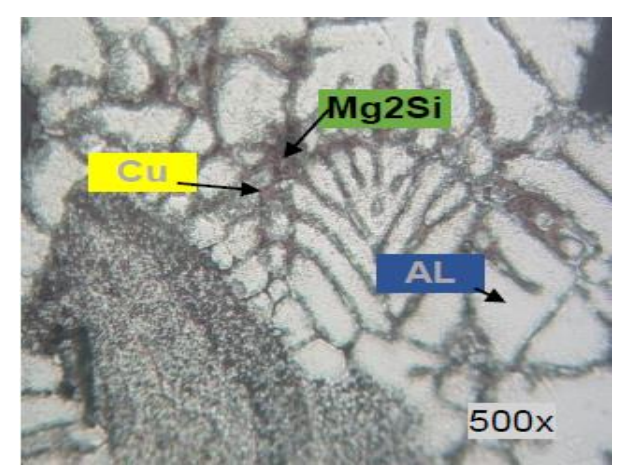

(a)

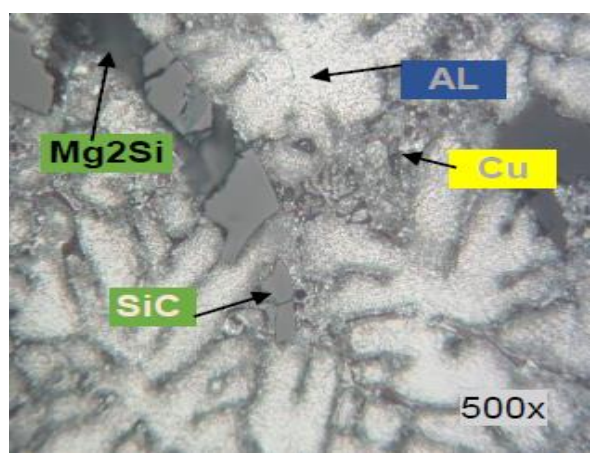

(c)

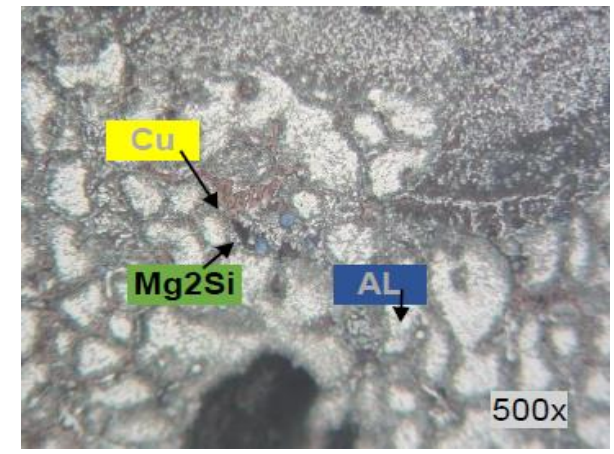

(b)

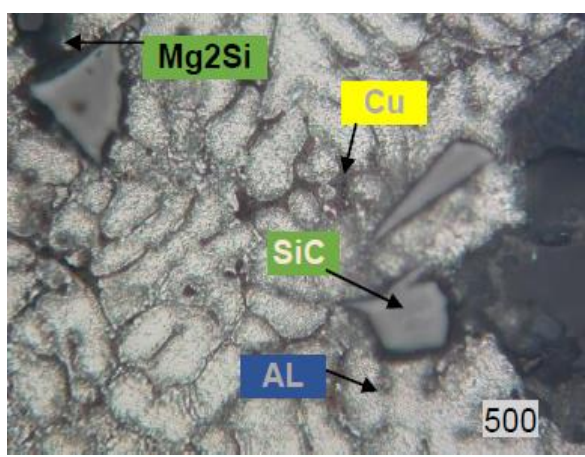

(d)

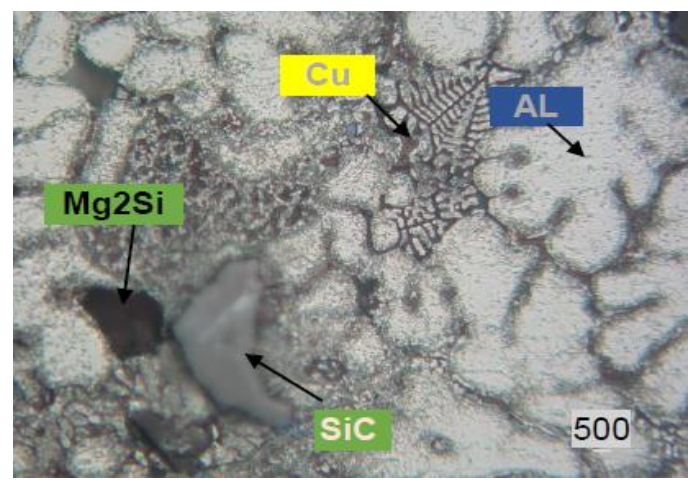

(e)

Gambar 4. Pengamatan struktur mikro (a) AMC non Aging (b) Aging pada temperatur $100^{\circ} \mathrm{C}$ waktu 1 jam (c) Aging Pada Temperatur $100^{\circ} \mathrm{C}$ waktu 2 jam (d) Aging pada temperatur $100^{\circ} \mathrm{C}$ waktu 3 jam (e) Aging pada temperatur $100^{\circ} \mathrm{C}$ waktu 4 jam 
Pada aging $100^{\circ} \mathrm{C}$ selama 1 jam terdapat fasa $\mathrm{Al}-\mathrm{Mg}_{2} \mathrm{Si}$ dimana fasa Alumunium (berwarna terang) dan $\mathrm{Mg}_{2} \mathrm{Si}$ (berwarna kelabu kehitam-hitaman). Terlihat bahwa partikel $\mathrm{Mg}_{2} \mathrm{Si}$ terdistribusi merata dan menyebabkan nilai kekerasan pada sampel aging $100^{\circ} \mathrm{C}$, pada $\mathrm{Al}-5 \% \mathrm{Cu}-4 \% \mathrm{Mg}$ dengan fraksi penguat $15 \%$ partikel $\mathrm{SiC}$, tampak bahwa $\mathrm{SiC}$ terdistribusi merata pada perlakuan aging $100^{\circ} \mathrm{C}$ fasa $\mathrm{Mg}_{2} \mathrm{Si}$ terlihat cukup merata sehingga menyebabkan nilai kekerasan pada sampel . Peningkatan sifat mekanik seperti nilai kekerasan dan tarik semata-mata tidak hanya dihasilkan dari terbentuknya presipitasi $\mathrm{Mg}_{2} \mathrm{Si}$ melainkan oleh adanya partikel $\mathrm{SiC}$ yang mengendap didalam paduan matriks $\mathrm{Al}$ $5 \% \mathrm{Cu}-4 \% \mathrm{Mg}$.

Sementara pada $\mathrm{Al}-5 \% \mathrm{Cu}-4 \% \mathrm{Mg}$ dengan fraksi penguat $15 \%$ partikel $\mathrm{SiC}$ yang melalui proses perlakuan aging $100^{\circ} \mathrm{C}$ selama 2 jam, terlihat bahwa $\mathrm{SiC}$ terdistribusi merata pada perlakuan aging dan fasa $\mathrm{Mg}_{2} \mathrm{Si}$ terlihat cukup merata sehingga menyebabkan nilai kekerasan. Peningkatan sifat mekanik seperti nilai kekerasan dan tarik semata-mata tidak hanya dihasilkan dari terbentuknya presipitasi $\mathrm{Mg}_{2} \mathrm{Si}$ melaikan oleh adanya partikel $\mathrm{SiC}$ yang mengendap didalam paduan matriks $\mathrm{Al}-5 \% \mathrm{Cu}-4 \% \mathrm{Mg}$.

untuk $\mathrm{Al}-5 \% \mathrm{Cu}-4 \% \mathrm{Mg}$ dengan fraksi penguat $15 \%$ partikel $\mathrm{SiC}$ yang melalui proses perlakuan aging $100^{\circ} \mathrm{C}$ selama 3 dan 4 jam, terlihat bahwa SiC terdistribusi cukup merata pada perlakuan aging fasa $\mathrm{Mg}_{2} \mathrm{Si}$ terlihat cukup merata sehingga menyebabkan nilai kekerasan pada sampel aging $100^{\circ} \mathrm{C}$ selama 3 dan 4 jam naik.

\section{KESIMPULAN}

Berdasarkan hasil pengujian dan analisa maka pada penelitian AMC dengan variasi temperatur waktu aging dapat di tarik kesimpulan sebagai berikut ini :

a. Waktu aging sangat berpengaruh terhadap kualitas AMC yang dihasilkan dimana semakin lama waktu aging semakin baik pula mechanical properties baik kekuatan tarik dan nilai kekerasannya, kenaikan kekuatan tarik sampai $70 \%$ dan kekerasan $31 \%$.

b. Sedangkan untuk variasi temperatur pengaruhnya tidak signifikan, bahkan mengalami penurunan, presentasi penurunannya sekitar $2 \%$ untuk nilai kakuatan tarik dan $10 \%$ untuk nilai kekerasan..

Studi mechanical properties dan struktur mikro hasil variasi temperatur dan waktu aging pada alumunium matrix composite (AMC) hasil proses stir casting dengan kandungan matrix berlebih (Iman Saefuloh, dkk.) 


\section{DAFTAR PUSTAKA}

[1] Surdia, T. dan CijiiwaK, Teknik Pengecoran Logam, Jakarta, PT Pradnya Paramita, 1991.

[2] Smith, F. William, Material Science and engineering, $2^{\text {nd }}$ ed., NewYork: Mc Graw-Hillinc, 1995.

[3] Widi Aprianto, et. al., Pemilihan bahan dan proses, Bandung, Universitas Jenderal Achmad Yani pers, 2014.

[4] Suyanto., Sulardjaka., Sri Nugroho, "Pengaruh Komposisi Mg dan SiC Terhadap Sifat Kekerasan Komposit AlSi-SiC yang dibuat dengan Proses Semi Solid Stircasting,” Universitas Diponogoro, 2017.

[5] Anne Zulfa, et. al., "Proses Penuaan (Aging) pada Paduan Aluminium AA 333 Hasil Proses Sand Casting," Universitas Indonesia, 2010.

[6] Juriah Mulyanti, "Pengaruh Temperatur Aging Terhadap Karakteristik Material Komposit Logam Al-SiC Hasil Stir casting", Universitas Janabadra, 2011.

[7] Fuad Abdillah, "Perlakuan Panas Paduan Al-Si pada prototype piston berbasis material piston bekas," Universitas Diponegoro, 2010.

[8] Supriatna, "Pengaruh Perlakuan Panas Dan Penuaan Terhadap Sifat Mekanis Pada Material Komposit Matrik Al-4,5\%Cu-4\%Mg-10\%SiC(P)," Universitas Gunadarma, 2017.

[9] Iman Saefuloh, et. al., "Studi Karakteristik Sifat Mekanik Alumunium Matrix Composite (AMC) Paduan AL, 5\% Cu, 12\% Mg, 15\% SiC Hasil Proses Casting dengan Variasi Temperatur Pengadukan, Jurnal Teknika Untirta Edisi 14 No. 2 Hal. 151 -164, 2018.

[10] Amir Arifin, et. al., "Pengaruh Parameter Stir casting Terhadap Sifat Mekanik Alumunium Matrx Composite (AMC)" Flywheel, vol. III, no. 1, pp. 21-31, 2017.

[11] Rieco Malik dan Sutaris., "Pengaruh Temperatur Aging dan Waktu Holding Aging presipitasi Hardening pada Struktur Mikro dan Sifat Mekanik Paduan Mg-5Al-1\%Y untuk Aplikasi komponen Otomotif Temperatur Tinggi" Institut Teknologi Sepuluh November, 2014. 